\title{
Editorial: The Authorship of IJMPCERO Papers
}

\author{
Maria F. Chan*, Chengyu Shi \\ Department of Medical Physics, Memorial Sloan Kettering Cancer Center, New York, NY, USA \\ Email: *chanm@mskcc.org
}

How to cite this paper: Chan, M.F. and Shi, C.Y. (2018) Editorial: The Authorship of IJMPCERO Papers. International Journal of Medical Physics, Clinical Engineering and Radiation Oncology, 7, 427-430. https://doi.org/10.4236/ijmpcero.2018.74035

Received: September 4, 2018

Accepted: September 25, 2018

Published: September 28, 2018

Copyright $\odot 2018$ by authors and Scientific Research Publishing Inc. This work is licensed under the Creative Commons Attribution International License (CC BY 4.0).

http://creativecommons.org/licenses/by/4.0/

\section{Introduction}

The International Journal of Medical Physics, Clinical Engineering, and Radiation Oncology (IJMPCERO) was founded in 2012 by Qinghui Zhang, PhD and his colleagues from the Memorial Sloan Kettering Cancer Center, New York, NY, USA. The Editor-in-Chiefs have been Lei Xing, PhD (Stanford University), Huan Bosco Giap, MD, PhD (Scripps Proton Therapy Center), and Ning Jeff Yue, $\mathrm{PhD}$ (Rutgers Cancer Institute of New Jersey). The journal has been endorsed by the North American Chinese Medical Physicists Association (NACMPA) since the beginning. It is an Open Access (OA) journal published quarterly, meaning that the publisher makes all articles and related content available for free on the journal's website.

Since it was established, the journal has published over 250 articles with more than 400 citations. Since it is an OA, there have been over 450,000 and 730,000 downloads and views of IJMPCERO articles respectively. For example, one of the early-published articles (G. Massillon-JL, et al., "Energy dependence of the new Gafchromic EBT3 film-Dose response curves for $50 \mathrm{kV}, 6$ and $15 \mathrm{MV}$ x-ray beams", 1(2): $60-65,2012$ ) has been cited by many other peer-review journals' articles more than 90 times based on Google Scholar Citations.

\section{Aims and Scope}

The goal of IJMPCERO journal is to provide a platform for scientists and academicians all over the world to promote, share, and discuss various new issues and developments in different areas of medical physics, clinical/biomedical engineering and radiation oncology. It provides an international forum for research, reviews, education and training on various topics in clinical trials, outcomes research, medical physics, medical dosimetry, diagnostic imaging, radiation protection, radiobiology, clinical/biomedical engineering, and radiation oncology. Publications may be in the form of a 1) Review Article, 2) Research Article, 3) Short Report, 4) A Rapid Communication, 5) Technical Note, 6) Correspondence, 7) Editorial, 8) Special Report or 9) Clinical Trials. 


\section{Authorship Guidelines}

The manuscript should be submitted by one of the authors of the manuscript through the online manuscript submission system

(https://www.scirp.org/journal/ijmpcero/). Regardless of the source of the word processing tool, electronic PDF or MS-Word files can only be submitted via the online submission system. Submitted manuscripts that comply with the journal guidelines will be reviewed by the editor or associate editor, who will assign them to the reviewers. The review process is single-blind. The editor prepares a decision letter based on the reviewer's comments and sends it to the appropriate author. All unaudited manuscripts will be returned within 10 days and the manuscript decision will be sent within 4 weeks.

Open Access authors retain the copyright of their papers, and all open access articles are distributed under the terms of the Creative Commons Attribution-Non-Commercial License CC BY-NC, allowing users (non-commercial) to appropriate attribution of identity, public copying, use, distribution, dissemination and display of works, and production and distribution of derivative works in any digital media for any responsible purpose.

IJMPCERO is an open access journal that is freely accessible on the Internet. The online publishing process does involve costs, including the setup and maintenance of the publication infrastructure, the day-to-day operations of the journal, the processing of manuscripts through peer review, editing, publishing, maintaining academic records and archiving related costs. In order to pay for these expenses, the journal relies on the article-processing fee (hereinafter referred to as APC), also known as the publishing fee. When the manuscript is accepted for publication, the APC is $\$ 599$. Authors who have previously published articles may be subject to some discounts.

As mentioned earlier, the journal was supported by the NACMPA. Thus, Best Paper Award ( $\$ 500$ voucher along with a framed official certificate) has been presented to the first author of the winning paper each year at the annual meeting of NACMPA since 2013. The meeting is held on Wednesday evening at the annual conference of American Association of Physicists in Medicine (AAPM). The articles published in IJMPCERO indexed by Google Scholars are highly and quickly seen by your peers in the same field. When you enter the keywords of the subject, your article would appear immediately on the top of the webpage. Therefore citations for IJMPCERO articles are increasing every year.

\section{Is My Article PubMed Indexed?}

IJMPCERO is currently not automatically indexed in PubMed database. For those authors who receive NIH research grants or relevant research funding, you could deposit your final accepted version of the article to PubMed Central ${ }^{\infty}$ (PMC) manually in order to acknowledge the funding sources as required. PMC is a free full-text archive of biomedical and life sciences journal literature at the US National Institutes of Health's National Library of Medicine (NIH/NLM). PMC was developed and is managed by NLM's National Center for Biotechnol- 
ogy Information (NCBI). PMC is a repository for journal literature deposited by participating journals, as well as for author manuscripts that have been submitted in compliance with the public access policies of participating research funding agencies.

For a step-by-step tutorial on completing the final approval, please visit:

Http://www.nihms.nih.gov/db/sub.cgi?page=stepbystep

Figure 1 and Figure 2 (Curtsey of NIH/USDHHS) show you the steps to

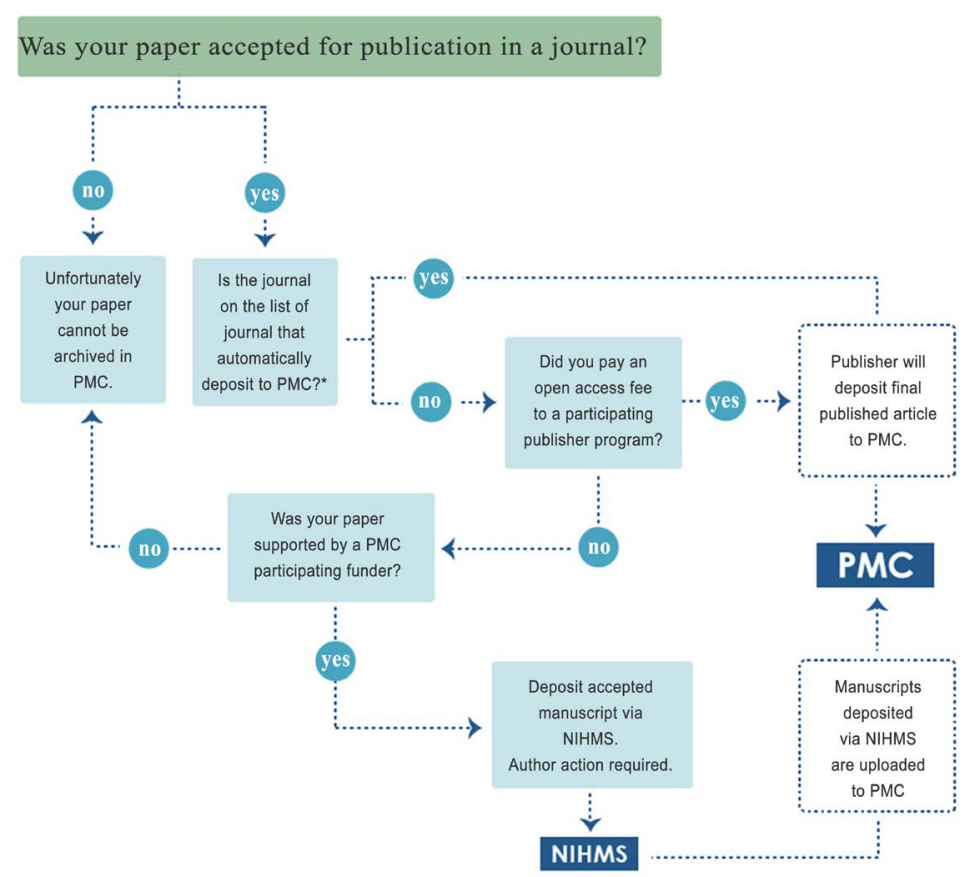

Figure 1. Scheme of manual submission to PMC (screenshot of the NIHMS).

NIH Manuscript Submission System

\section{Sign In}

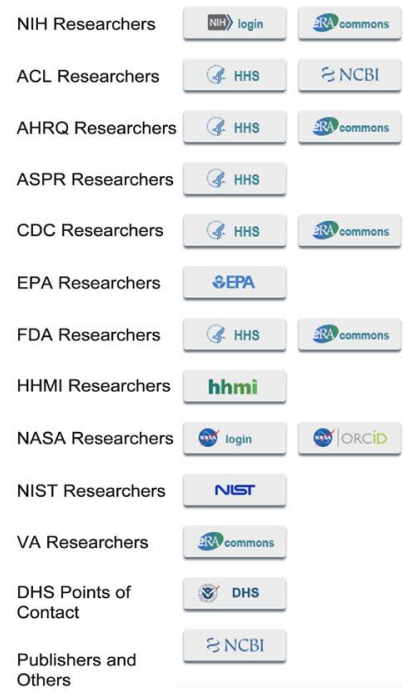

NIHMS Process

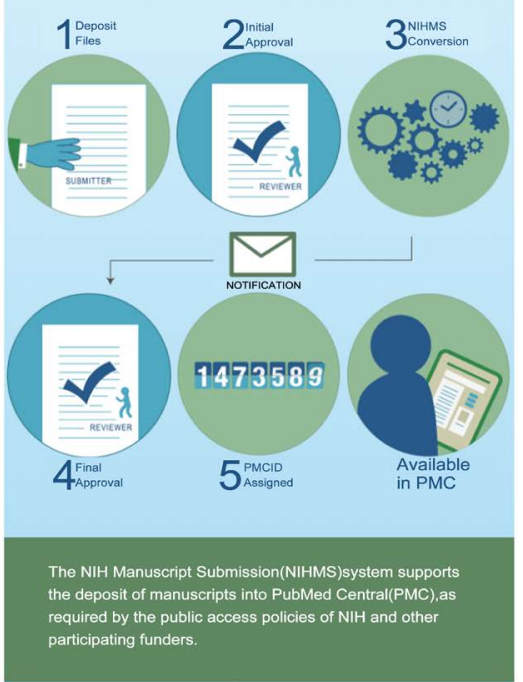

Figure 2. NIH manuscript submission process (screenshot of the NIHMS). 
deposit your manuscript to NIH/NLM database after your article is accepted for publication in IJMPCERO. If you still have any questions, please contact the NIHMS help desk for assistance via

Http://www.nihms.nih.gov/db/sub.cgi?.page=email

We hope this gives you a better understanding of the process by which a manuscript is reviewed by the IJMPCERO and deposited in the NIH/NLM system. The editorial board looks forward to serving both medical physics and radiation oncology authors to publish the highest impact cancer research to our worldwide clinical/scientific readership.

\section{Acknowledgements}

This work was funded in part through the NIH/NCI Cancer Center Support Grant P30 CA008748. 